\title{
O CAMPESINATO NA AMAZÔNIA ORIENTAL A PARTIR DAS CONCEPÇÕES TEÒRICAS DO SOCIALISMO: A GARIPERIZAÇÃO DO POSSEIRO
}

\section{THE PEASANT IN THE EASTERN AMAZON FROM THE THEORETICAL CONCEPTIONS OF SOCIALISM: THE GARIPERIZATION OF THE POSSESSOR}

\author{
Glilbson Barbosa SOUSA ${ }^{1}$ \\ Elizeu Ribeiro LIRA ${ }^{2}$
}

\begin{abstract}
Resumo: Este artigo busca apresentar de maneira sucinta as concepções acerca do campesinato, a partir das concepções do socialismo. Seu principal objetivo é expressar como o campesinato se estrutura como classe social na Amazônia Oriental, a partir da metamorfose do posseiro em garimpeiro, e seu retorno à luta pela terra nos seios dos movimentos sociais. Sendo assim uma nova articulação no que se liga à luta de classe, que vem sofrendo diretamente com as interposições do capital fundiário. Essa, busca a monopolização do território em prol da acumulação de capital, a qual manifesta ação de expropriação, de dominação e, consequentemente, de expulsão de membros de uma classe social, os camponeses, que manifestam suas ações para que a condição de manutenção, de permanência e de reingresso a terra, em um processo de metamorfose seja proporcionando a manutenção de ideias vivas, seja mantendo viva sua identidade e, assim, vinculando o passado e o presente na luta para subsistir como camponês amazônico.
\end{abstract}

Palavras-Chaves: Campesinato; Expropriação; Amazônia Oriental.

Abstract: This article seeks to present in a succinct way the conceptions about the peasantry, from the conceptions of socialism. Its main objective is to express how the peasantry is structured as a social class in the Eastern Amazon, based on the metamorphosis of the squatter into a garimpeiro, and his return to the struggle for land in the breasts of social movements. Thus, it is a new articulation with regard to the class struggle, which has been suffering directly from the interpositions of land capital. This seeks to monopolize the territory in favor of capital accumulation, which manifests an action of expropriation, domination and, consequently, expulsion of members of a social class, the peasants, who manifest their actions so that the condition of maintenance of permanence and re-entry to land, in a process of metamorphosis, either by keeping ideas alive, or by keeping their identity alive and, thus, linking the past and the present in the struggle to survive as an Amazon peasant.

Keywords: Peasantry; Expropriation; Eastern Amazon.

\section{Introdução}

As transformações que ocorreram na sociedade contemporânea, no que diz respeito aos processos de organização campesina, estão vinculadas principalmente em virtude da globalização, ao crescimento da produção industrial capitalista, que acarretaram em modificações especificamente quando o foco passa a ser a vida de diversas famílias camponesas que se tornaram vítimas, em um longo período, em que se observa transformações na sociedade em detrimento do capitalismo estrutural, que modifica a

\footnotetext{
${ }^{1}$ Mestre em Geografia pela Universidade Federal do Tocantins - UFT.

${ }^{2}$ Prof. Dr. do PPGG- Pós-Graduação, em Geografia da Universidade Federal do Tocantins - UFT.
} 
realidade a partir do momento em que se tem a instituição de uma produção na agricultura industrial.

As ações do capitalismo industrial modificam a realidade da produção campesina, e tais transformações são vinculadas às imposições dos agentes concentradores de capital. Nessa perspectiva de modificação, Kautsky (1998) discorre que as ações dos capitalistas não poderiam estar vinculadas à outras classes, que eram representadas pela burguesia e pelo proletariado.Nesse sentido, Karl Marx (2017, p. 678) ${ }^{3}$ caracteriza a subordinação da produção ao sistema capitalista como condição em que se cria a reprodução da propriedade privada de forma efetiva e devastadora da realidade do camponês,camponês que outrora era representante do processo de produção como reprodução do modo de produzir no processo de subsistência.

Como destacado por José Paulo Netto (1982), os camponeses que lutavam no processo de manutenção de sua permanência da terra viam que "a economia rural e as instituições camponesas eram vigorosos antídotos contra o capitalismo" (apud LÊNIN, 1982, p.12), levando então à busca constante do camponês por seu espaço no território, buscando sua permanência e manutenção constante.

As condições tais como expressas por Lênin (1982, p. 7), ao destacar que o pequeno camponês existe na sociedade capitalista devido (principalmente) ao fato de reduzirem suas necessidades a um nível inferior a dos operários assalariados, ficando assim exauridos no trabalho, em comparação a esses operários que vendem sua força de trabalho ao grande capitalista, com o único objetivo de receber um salário em troca de tais ações.

Tal visão apresenta a forma na qual o capitalismo imputa sobre os camponeses sua força, acarretando em uma desvirtuação completa do modo não capitalista de produção. Nessa perspectiva, destacamos Kautsky (1998, p. 28) que analisa que "o desenvolvimento só é progresso quando não se limita a negar ou suprimir, e também quando conserva". Entretanto, as ações responsáveis pela criação da indústria no campo acarretaram em uma transformação no processo de produção agrícola que modifica todas as relações existente entre o camponês e o mercado, através de um desenvolvimento desigual. Tal podemos verificar, quando Kautsky (1998) apresenta que devemos admitir que

\footnotetext{
3 "Um dos grandes resultados do modo de produção capitalista é que, por um lado, ele transforma a agricultura, de mero procedimento tradicional, de natureza empírica e mecânica, praticado pela parte menos desenvolvida da sociedade, numa aplicação científica consciente da agronomia, na medida em que isso é possível, em geral, dentro das condições dadas com a propriedade privada." (MARX, 2017, p. 678).
} 
“[...] é fato comprovado, doravante, que a agricultura não se desenvolve, em absoluto, como cópia fiel da indústria, mas de acordo com suas próprias leis. Isso significa, de forma alguma, que o desenvolvimento da agricultura se opõe ao da indústria de forma inconciliável.” (KAUTSKY, 1998, p. 36)

Podemos ainda encarar a realidade do fato comprovado que o desenvolvimento da agricultura levou ao crescimento da indústria do campo, o que condicionou ao processo de modificação da relação do camponês com o campo, em que a expansão do latifúndio criou um novo panorama, no qual as frentes se apresentavam como mecanismo de modificação da realidade. Tal fato leva a constante de que o campesinato cria uma nova realidade onde o campo passa por transformações constantes.

Essa constante nos leva a entender ainda que, quando observamos a visão da junção entre agricultura e indústria, verificamos as transformações que modificaram a realidade do campesinato. Nesta perspectiva, observamos, ainda segundo KAUTSKY (1998, p. 36), que quando "acreditamos muito mais poder mostrar que ambas visões, o mesmo alvo quando não se procura isolá-las uma da outra e se as considera membros pertinentes a um mesmo processo conjunto", o que significa que a agricultura camponesa sofre com as imposições do capitalismo, ao ponto de que se criem novos panoramas em que a permanência se transforme e se modifique sempre.

Lênin (1988, p. 16) elucidar que aquele camponês patriarcal que outrora participava de uma economia predominantemente natural, ao se arruinar em virtude das manifestações do mercado capitalista, tende a recorrer a venda de sua força de trabalho mesmo que apenas para a manutenção dos meios de sua subsistência, colocando ainda que a partir desta "[...] transformação do pequeno produtor em operário assalariado pressupõe a perda dos seus meios de produção (terra, instrumentos de trabalho, oficina, etc.) - ou seja, pressupõe o seu “empobrecimento", a sua "ruína”". Kautsky (1998) destaca ainda que,

\footnotetext{
"Quanto mais a produção agrícola se transformava em produção de mercadorias, menor era sua condição de conservar o primitivo nível da venda direta do produtor ao consumidor. Quanto mais distantes e extensos se tronavam os mercados para os quais produzia o homem do campo, mais difícil se tornava, para ele, a venda direta ao consumidor e tanto mais necessário se tornava o intermediário". (KAUTSKY, 1998, p. 41)
}

As transformações no campo, em que a realidade camponesa se transforma cria uma composição diferente da rotina do camponês. Tal implicação cria um modo onde a subordinação ao sistema de produção capitalista, encontra-se ligando diretamente a desintegração do campesinato, mediante a assimilação deste sistema de maneira a se integrar 
por completo e, com isso, proporcionar a desconstrução do modo não capitalista de produção utilizado pelo campesinato. Sobre esse processo de transformações que o campesinato vem sofrendo ao longo dos anos, Shanin (2005) fala da "agriculturização" do campesinato:

"Por exemplo, a comercialização tem resultado, em geral, inicialmente em um estágio de "agriculturação" do camponês, fazendo com que suas tarefas não-agrícolas anteriores sejam assumidas pela produção industrial em massa (enquanto os aldeões são, frequentemente, jogados nas redes de exploração de empresas agrícolas capitalistas, de vários tipos)”. (SHANIN, 2005, p. 4)

A produção criada a partir do objetivo de levar ao camponês condições de continuação na terra, assim como descrito por Shanin (2005), nos leva a pensar a respeito do processo de agricultura camponesa que cria uma nova condição, na qual o sistema coletivo cria uma alternativa de manutenção destes camponeses na terra, e isso nos leva a perceber que a exploração, através do latifúndio, não terá sua força de imposição quando o sistema coletivo do campesinato criar uma alternativa que o leve a se manter dentro do território, e assim criar uma nova forma de articulação. Shanin (2005) descreve ainda acerca dessa coletivização:

"Do outro lado, a coletivização levou a uma variedade de padrões especificamente camponeses e de ação e reação, por exemplo, os padrões diferenciais de produção no terreno doméstico em oposição à área coletiva e seu impacto sobre as atuais esferas sociais da agricultura. Pode-se também mencionar, aqui, a recorrente surpresa diante da tenacidade das formas sociais camponesas (o "problema do não desaparecimento") e, mesmo, a "recamponesação" de algumas áreas." (SHANIN, 2005, p. 4)

O processo de re-camponesação das áreas, pelos camponeses que outrora encontravam-se expropriados, é o processo de manutenção de uma classe social que em grande parte sofre com generalizações de transformações impostas pelos dos meios de produção capitalista. Para Shanin (2005, p. 4), a generalização dos sofrida pelo camponês pode criar uma marginalização estrutural, o que levaria a uma nova visualização do camponês, e que não se liga diretamente ao campesinato enquanto classe social. Deste modo é possível perceber que

"A especificidade do camponês reflete a interdependência entre os elementos básicos mencionados e não pode ser pura e simplesmente reduzida a qualquer um deles. Ao mesmo tempo, o cerne de suas características determinantes parece repousar na natureza e na dinâmica do estabelecimento rural familiar, enquanto unidade básica de produção e meio de vida social. Consequentemente, a própria existência do camponês, como uma entidade social específica, depende da presença de estabelecimentos rural familiares como a unidade básica da economia e da sociedade". (SHANIN, 2005, p. 5) 
O camponês enquanto classe caracteriza sua luta e sua vida como transformação da vida social, transformações em decorrência das imposições do sistema capitalista, uma característica que proporciona uma decomposição do campesinato. Lênin (1988) analisa a decomposição do campesinato, a partir da caracterização de algumas categorias que apresentavam visões acerca do campesinato, e dessa maneira pode-se observar categoria dos capitalistas, compreendendo os camponeses enriquecidos, os cultivadores mercantis independentes e os proprietários de estabelecimentos industriais e comerciais; a dos camponeses médios, de economia mercantil menos desenvolvida e suscetível a proletarização; e a dos operários agrícolas, possuidores de um pedaço de terra ou sem-terra e que se viam obrigados a alugar sua força de trabalho. Portanto, compreende-se que

“[...] a transformação do campesinato em proletariado rural cria um mercado principalmente para os artigos de consumo, e a sua transformação em burguesia rural cria-o principalmente para os meios de produção. Noutros termos: nos grupos inferiores "do campesinato", verifica-se a conversão da força de trabalho em mercadoria e, nos grupos superiores, a conversão dos meios de produção em capital." (LÊNIN, 1988, p. 108).

Cria-se então uma nova estruturação dos sistemas de organização, na qual o proletariado rural propicia uma transformação nos modos de organização campesina em que os meios de produção do campesinato se tornam ineficientes perante tais ocorrências do sistema produtor capitalista. A partir daí podemos verificar a teoria dos sistemas econômicos não capitalistas de Chayanov, para que possamos compreender como se deram as transformações do campesinato na primeira metade do século XX, na Rússia.

No que tange em proporcionalidade da população campesina durante a primeira década do século XX, na Rússia, era perceptível a constituição de uma população agrária em todo o território do país. Após a Revolução de 1917 e a consolidação do socialismo/leninismo, a propriedade privada (de terras), desde a pequena, a média e grande propriedade), foi submetida ao intenso processo de expropriação e nacionalização fundiária, em decorrência do processo de industrialização do campo.

Chayanov (2014) busca apresentar a composição da ideia de que a existência de variados sistemas econômicos dentro da sociedade Russa, como em outras sociedades, vincula-se ao processo de omissão dos fatores não cruciais para o entendimento do sistema de articulação da sociedade capitalista, que se liga diretamente ao processo de acumulação, no qual o preço dos produtos, a renda média tirada deste investimento em capital fixo, resultaria em um lucro para este capitalista industrial. 
A partir do modo de produção capitalista, observamos uma composição de mecanismos que podem tornar o modo de produção não capitalista, que no caso são os modos de produção campesina passando por transformações, como é destacado por Chayanov, ao falar que

\begin{abstract}
"Outros tipos - não capitalistas - de vida econômica seriam consideradas destituídas de importância ou em vias de desaparecimento; de qualquer modo, considera-se que não tem qualquer influência nos problemas fundamentais da economia moderna, e que por conseguinte, que não apresentam qualquer interesse teórico."(CHAYANOV, 2014, p.99)
\end{abstract}

Cabe aqui, então, perceber que os mecanismos que se aplicam ao processo de articulação dos modos de produção camponesa tendem a desaparecer em decorrência de uma nova formação de modos de apropriação por parte dos capitalistas industriais. Para que tal fato não ocorresse, Chayanov (2014, p. 100) compõe a teoria de criação de uma econômica camponesa ligada a uma lógica interna em que o trabalho familiar seja a base da produção. Assim como numa forma não capitalista, estaria baseada em uma "forma completamente diferente: a da exploração familiar sem assalariados. Uma exploração desse tipo tem razões muito precisas para se entregar à atividade econômica; e tem também uma concepção muito especial das possibilidades de lucro.” (CHAYANOV, 2014, p. 100).

Tomando do ponto de partida que a exploração camponesa se dá a partir da implantação do capitalismo industrial rural, Chayanov (2014, p. 100) apresenta uma visão de que a maior parte das explorações camponesas existentes em algumas partes do mundo tendem a ignorar algumas prerrogativas, que são o trabalho assalariado e de salário propriamente dito. Nessa perspectiva, sobre as categorias econômicas Chayanov ainda vem afirmar alguns fatos:

"[...] um sistema complexo de categorias econômicas - preço, capital, salário, juro, renda -, todas elas estreitamente ligadas umas às outras, determinando-se mutuamente e funcionalmente interdependentes. Se se tirar uma pedra desta construção, todo o edifício desmorona. Na ausência de qualquer destas categorias, todas as outras perdem o seu caráter especifico e o seu conteúdo conceitual; já não podem sequer ser definidas quantitativamente." (CHAYANOV, 2014, p.100)

E essa interdependência proporciona uma nova visualização de como o sistema capitalista de produção se estrutura, e constitui uma visão de que, mesmo sendo diferentes, todos estão num mesmo lugar, lugar em que quem recebe os honorários dos trabalhos presentes dentro deste território são os acumuladores de capital. Assim, podemos verificar que 
no que diz respeito a uma economia que, com exploração no trabalho familiar, seria um mecanismo que se liga proporcionalmente ao salário sobre a força de trabalho empregada para a execução de tal atividade. Seguindo tal viés, Chayanov coloca que

\begin{abstract}
"O camponês ou o artesão que gere a sua própria empresa, sem recurso ao trabalho assalariado, obtém, como resultado do trabalho de um ano, uma quantidade de produtos que, depois de vendidos no mercado, formam o produto bruto da sua exploração. Deste produto bruto temos de deduzir uma soma correspondente aos custos de produção materiais necessários durante um ano; fica então o aumento de bens materiais em valor obtido pela família, graças ao seu trabalho do ano." (CHAYANOV, 2014, p. 105)
\end{abstract}

Observamos, então, que na prevalência de uma economia camponesa de produção familiar não se encontra presente a visualização da categoria como salário, por não haver, nesse modo de produção camponesa, a presença da exploração por parte de um único dono desses mecanismos de produção.

Nesse contexto, cria-se uma nova maneira de exploração das forças de produção condição que leva em conta o tempo em que a "exploração com base no trabalho familiar, a família, equipada de meios de produção, utiliza a sua força de trabalho para cultivar o solo e obtém, como resultado do trabalho de um ano, uma certa quantidade de bens" (Chayanov, 2014, p. 105),o que leva a composição de uma identidade em que a quantidade de bens produzidos leva uma nova condição, condição que possibilita ao camponês a uma ligação com a terra. Chayanov $(2014)^{4}$, o que leva, por sua vez, ao processo de exploração da terra.

A partir daí, Chayanov (2014) afirma que, nessa forma de utilização do trabalho familiar camponês, torna-se o produto do trabalho apenas uma categoria, a que se liga diretamente aos possíveis rendimentos para a exploração camponesa, visto que não existe uma maneira de decomposição deste rendimento, devido, principalmente, ao fato da inexistência de uma acumulação final de lucro por parte dos camponeses. Nesta constituição de valorização do trabalho familiar, Chayanov (2014) destaca que

\footnotetext{
“[...]a importância do produto do trabalho é principalmente determinada pela dimensão e composição da família, ou seja, o número de pessoas da família capazes de trabalhar pela produtividade da exploração e - o que é particularmente importante - pelo grau de autoexploração, graças ao qual os ativos fornecem uma certa prestação de trabalho ao longo do ano." (CHAYANOV, 2014, p. 106)
}

\footnotetext{
${ }^{4}$ Uma olhadela apenas para a estrutura interna dessa exploração bastaria para nos fazer perceber que, na ausência da categoria salário, é impossível situar nesta estrutura o lucro líquido, a renda e o juro do capital, considerados como verdadeiras categorias econômicas no sentido capitalista do termo. (CHAYANOV, 2014, p. 105).
} 
Tal visualização teórica de que o grau de auto exploração é determinado por um quantitativo, no qual a relação de des-satisfação ocorrida pela procura familiar e a fadiga devido ao trabalho constituem uma realidade que se torna de alguma forma equilibrada quando se colocam lado a lado nesta perspectiva de auto exploração da força de trabalho. Chayanov (2014) assegura que está ligada diretamente esta variação de equilíbrio em que

[...]por um lado, a partir das condições específicas da unidade de produção, da sua situação no plano do mercado e da sua localização relativamente aos locais de troca (tudo isto determina o grau de esforço fornecido); por outro, a partir da dimensão e composição da família, bem como do caráter mais ou menos urgente de suas exigências - dados que determinam o nível de consumo. (CHAYANOV, 2014, p.107)

Assim, podemos observar que, a partir das análises de Chayanov, o camponês enquanto dono de seus meios de produção, através do trabalho familiar adquire uma nova modificação da sua relação com o sistema capitalista, em que a venda de sua força de trabalho para o grande proprietário, acumulador de capital, não resultará em uma exploração de sua força de trabalho mediante a troca por salário. A partir daí, vemos que as novas organizações proporcionam uma nova estruturação do camponês, em se falando dos mecanismos de produção.

\footnotetext{
"A intensidade e as formas de organização da cultura dependem, numa larga medida, da quantidade de terra utilizável, da dimensão da família trabalhadora e da importância da sua procura, ou seja, fatores internos: dimensão e composição da família, relação entre tais elementos e a quantidade de terras cultiváveis. Assim, a densidade da população e as formas de utilização tornam-se fatores sociais extremamente importantes, que determinam de maneira fundamental o sistema econômico." (CHAYANOV, 2014, p. 115 e 116)
}

O camponês passa, então a uma organização produtora familiar que é a base de uma estrutura que se vincula diretamente ao lado cultural destas famílias, uma dimensionalidade em que os elementos são a base de uma quantidade de produção nas terras cultiváveis advindas da proporcionalidade de subsistência da área em que o camponês agora está ligado, a terra que outrora foi retirada de seu poder, e na qual pôde realizar as iniciativas de estruturação para que atenda às necessidades da família são supridas através desta organização da produção familiar. 


\section{A estruturação do campesinato brasileiro: um esforço teórico para compreender sua dinâmica na Amazônia Oriental}

No que tange a história da geografia agrária no Brasil, verificamos uma quantidade de variados pesquisadores que buscam compreender as transformações que a agricultura camponesa veio sofrendo ao longo da história, em virtude do modo capitalista de produção. Deste modo, em cada caracterização da estrutura do campesinato brasileiro, partimos da análise de dois teóricos que abordam a questão do campesinato brasileiro: José de Souza Martins e Ariovaldo Umbelino de Oliveira, teóricos que caracterizam o campesinato no Brasil e seus embates, a partir das imposições sofridas com o modo de produção capitalista.

Martins (1983) nos apresenta que as ações de organização e modificação das estruturas mediante a nova imposição do sistema capitalista de produção proporciona então a exclusão do camponês, fato ligado ao processo de estudo em que a agricultura brasileira se transforma e proporciona assim uma nova transformação, e que fica intrinsecamente ligada ao processo de expropriação do camponês e também cria uma visão de que o modo de produção capitalista é ao mesmo tempo contraditório e combinado à acumulação de capital. Oliveira $(1999$, p.73) enfoca que o desenvolvimento capitalista no campo é um processo que se difere do que ocorre na agricultura brasileira, sendo em detrimento das interligações existentes nos pactos políticos que o Estado mantém uma nova composição das estruturas, nas quais tais ações políticas proporcionam a exclusão de uma classe e o favorecimento de outro. E em continuação a esse ponto de vista Oliveira $\left(1999\right.$, p.73) ${ }^{5}$ apresenta que essas relações são continuas e se transformam quando o capital rentista modifica realidade da população campesina.

A partir daí, podemos verificar, assim como evidenciado por Martins (1980), que "quando o capital se apropria da terra, essa se transforma em terra de negócio, em terá de exploração do trabalho alheio; quando o trabalhador se apossa da terra, ela se transforma em terra de trabalho" (MARTINS, 1980, p. 60). Assim, o camponês enquanto agente produtor constitui uma relação com a terra que se liga diretamente ao seu usufruto, e sobre a qual manterá essa relação.

\footnotetext{
${ }^{5} \mathrm{O}$ estudo da agricultura brasileira deve ser feito levando-se em conta que o processo de desenvolvimento do modo capitalista de produção é contraditório e combinado. Isso quer dizer que, ao mesmo tempo que esse desenvolvimento avança reproduzindo relações especificamente capitalistas (implantando o trabalho assalariado para presença do bóia-fria), ele (o capitalismo) produz também, igual e contraditoriamente, relações camponesas de produção (pela presença do aumento do trabalho familiar no campo). Entre os mais importantes pensadores dessa corrente estão Rosa de Luxemburgo, Teodor Shanin, Samir Amin, Kostas Vergopoulos (...). (OLIVEIRA, 1999, p.73).
} 
No caso do camponês brasileiro que aparece em meio a essa formação social, apesar do caráter capitalista dessas relações, mantem-se relações de produção alheias ao modo de produção que era dominante dentro da sociedade. E em decorrência disto, podemos, como diz Martins, elencar que o campesinato nacional "tem, na sua relação com o capital, contradições diferentes daquelas que tem o operário" (MARTINS, 1983, p. 16), e que, sobretudo no Brasil, “O camponês não é uma figura do passado, mas uma figura do presente da história capitalista do país" (MARTINS, 1983, p. 16).

Diferentemente do campesinato europeu, que tem suas origens derivadas do modo de produção feudal, o camponês brasileiro é uma criação do próprio modo de produção capitalista. Desta maneira, Martins (1983) destaca as ideias defendidas por Lênin, nas quais o campesinato Brasileiro é um campesinato pautado em entrar na terra, diferentemente do campesinato Russo, no qual o camponês era proprietário de suas terras, e lutava assim para permanecer nela, mesmo com o avanço dos modos de produção capitalista sobre o campo:

"Lá, o campesinato resistia à expansão do capital porque era um campesinato apegado, ligado à terra. Era [...] um campesinato estamental baseado na propriedade comunitária e tradicional da terra. Lá, era um campesinato que não queria sair da terra, que queria permanecer defensivamente alheio ao capitalismo, fora e contra ele, que resistia ao processo de expropriação que poderia desenraizá-lo, libertá-lo da comuna, abrir-lhe os horizontes. Aqui, ao contrário, o campesinato é uma classe, não um estamento. É um campesinato que quer entrar na terra, que, ao ser expulso, com frequência à terra retorna, mesmo que seja distante daquela de onde saiu. O nosso campesinato é constituído com a expansão capitalista, como produto das contradições dessa expansão." (MARTINS, 1983, p. 15$16)$.

Essa contradição representa um fator histórico, que marca a formação social brasileira, criada a partir da ocupação do território pelos desbravadores portugueses. Passa-se, então, por períodos em que se marcam o desenvolvimento do camponês que luta pela sua reinserção na terra, períodos do Brasil colônia, da escravização indígena e sua proibição em 1757, partindo daí para um processo em que uma parcela da população parte a se agregar a grande propriedade sesmarial, originando da figura do agregado, o precursor do camponês atual.

Martins (1983) fala ainda que só uma classe se mantém em constante beneficiamento, enquanto outra encontra-se em declínio, processo acarretado diretamente pelo de usufruto de uma terra, que proporciona o enriquecimento dos donos dos meios de produção capitalista. Devido a isso, ocorre uma nova caracterização do ser enquanto camponês, camponês que sofre com esse processo. 
“O escamoteamento conceitual é o produto necessário, a forma necessária e eloquente da definição do modo como o camponês tem tomado parte no processo histórico brasileiro - como um excluído, um inferior, um ausente que ele realmente é: ausente na apropriação dos resultados objetivos do seu trabalho, que aparece como se fosse desnecessário, de um lado, e alheio, de outro lado." (MARTINS, 1983, p.25)

Esse escamoteamento leva a compreensão de que a sociedade capitalista, que se encontra interessada na expansão do modo de produção capitalista, com o apoio do Estado para tal implementação, condiciona o camponês a um reles trabalhador do campo que, como excluído, encontra-se submetido à venda de sua força de trabalho e, com isso, sob o julgo das ações dos proprietários dos modos de produção.

Nestas perspectivas de compreensão do que vem a ser o campesinato e de como ele deve ser encarado, destacamos Martins (1983, p.16), que caracteriza o campesinato como classe e não como um estamento, mesmo que não siga o sistema campesino característico europeu, no qual o camponês pertence a terra, e luta para continuar. O camponês do Brasil, em sua maioria, já não tem mais terra, e, portanto, encontra-se no processo de luta para se inserir em novo território, muitas vezes distante de onde se origina.

As marchas de resistência contra as imposições do capital ocorrem com o objetivo de proporcionar ao camponês seu retorno à terra. Nesta perspectiva Martins (1983) evidencia que

\footnotetext{
"As primeiras formas de luta e resistência camponesas ocorreram já nesses primeiros anos de República, que foram também anos de intensas e generalizadas lutas de coronéis contra coronéis em todo o país, verdadeiras guerras, que terminarão o seu ciclo de maior vitalidade com a Revolução de Outubro de 1930 e o início da centralização do poder." (MARTINS, 1983, p. 49).
}

A constituição de uma força de resistência compõe uma nova estrutura para dar força a luta camponesa, constituindo-se, então, em uma nova composição. Martins parte para uma definição de duas palavras que são características da luta campesina contra o sistema capitalista: camponês e latifundiário. "[...] são, palavras políticas, que procuram expressar a unidade das respectivas situações de classe e, sobretudo, que procuram dar unidade às lutas camponesas" (MARTINS, 1983, p. 23-24). Na verificação desses fatos, podemos observar que o camponês, enquanto membro de uma classe social, entra em confronto direto com o latifundiário, o dono dos meios de produção, criando assim um movimento de resistência constante.

O que se evidencia, em relação a organização do campesinato brasileiro, é que seu início se deu a partir do período colonial, caracterizando-se como um campesinato advindo de 
uma colônia de trabalhadores que outrora encontravam-se em processo de escravidão. E nessa mesma perspectiva observamos que Martins (1983) vem nos falar a respeito do camponês mestiço, descendente de escravo, que vinha na luta pela introdução e continuação no processo de produção sem se adentrar no modo capitalista de produção.

\begin{abstract}
"A massa dos excluídos constituída durante o período colonial não era, pois, massa indiferenciada. Isso permitia a um branco deserdado pelo morgadio abrir a sua própria posse, onde pudesse, e obter assim a sua sesmaria. Já um mestiço pobre podia abrir a sua posse, mas, devido aos mecanismos tradicionais de exclusão que alcançavam o impuro de sangue, dificilmente poderia tornar-se um sesmeiro". (MARTINS, 1983, p. 34).
\end{abstract}

Em virtude dos processos de concessão de terras, observamos que durante o período colonial via-se a criação de sesmaria, com suas precedências legais, o que proporcionava o direito sobre a posse e usufruto desta terra. Martins (1983), no que correspondia a posse das terras para o fazendeiro, afirma que ela condizia com uma legitimidade comprovada através do título de sesmaria. Dessa maneira, o mesmo que detinha o poder sobre a terra, sobre os meios de produção, era quem não proporcionava ao camponês o direito a posse, do próprio mestiço. Eles adquiriam seus direitos mediante a efetivação, através do nome do fazendeiro que detinha o poder sobre a sesmaria.

Deste modo, os camponeses só teriam seus direitos evidenciados a partir de uma extensão dos direitos dos fazendeiros, sendo, assim, agregados destes que detinham o poder sobre a terra. A partir daí, Martins apresenta que as relações entre a posse da terra e o trabalho escravo tinham ligação de maneira a se transformar na realidade do camponês que buscava seu pedaço de terra para plantar. As realidades começam a mudar com

“[...]a independência do território, em 1822, não representou um colapso para as relações coloniais. O monopólio da terra não se constituía na condição do trabalho escravo; ao contrário, a escravidão é que impunha a necessidade do monopólio rígido e de classe sobre a terra, para que os trabalhadores livres, os camponeses, mestiços, não viessem a organizar uma economia paralela, livre da escravidão e livre, portanto, do tributo representado pelo escravo, pago pelo fazendeiro aos traficantes, já que a concorrência do trabalho livre tornaria economicamente insuportável o trabalho escravo". (MARTINS, 1983, p.37-38)

Em se tratando de quem utilizava a terra, e tendo o trabalho familiar como o principal mecanismos de constituir sua subsistência, Martins (1983, p.39-40) proporciona uma observação em que há uma gama de membros dessa composição, os quais se destacavam tanto os posseiros que utilizavam daquela terra mas não detinham o poder sobre ela, ficando 
assim sujeitos a expulsão, e os sitiantes que se tratavam dos pequenos agricultores independente, os proprietários donos de sítio - um lugar na terra -, agricultores itinerantes, sendo as feiras como lugar privilegiado do comércio.

Martins (1983) ainda apresenta a análise de que a grilagem das terras de posseiros é advinda diretamente da renda territorial de terras que outrora não existiam. E quando se trata de grilagem, podemos identificar que tais indivíduos não se encontravam apenas na tentativa de assegurar o monopólio de classe sobre a terra a partir da titulação das propriedades, seja por apadrinhamento estatal, seja por falsificação documental em cartórios, criação que buscavam adquirir a própria renda fundiária convertida imediatamente em capital.

Ao nos depararmos com uma estruturação política de luta pela manutenção de uma classe social, verificamos que o campesinato, dentro do território brasileiro, é caracterizado por um conjunto de embates, no qual o camponês está em luta constante contra as imposições do sistema capitalista, em luta contra a expropriação e contra o poderio do latifundiário. A partir de tais composições de luta contra as imposições do sistema capitalista, Martins (1983, p. 81) evidencia que, quando se trata da "história política do campesinato brasileiro, não se pode reconstruí-la separadamente da história das lutas pela tutela política do campesinato”, o que fica evidentemente caracterizado por uma constante luta por parte dos defensores de uma estruturação mais adequada da distribuição de terras para os camponeses.

Mediante essa argumentação, Martins (1983) ressalta que as lutas camponesas pela reforma agrária ficaram evidenciada e tomou um pouco mais de fôlego com a criação das Ligas Camponesas, que a partir de 1950 começam seus processos de atuação para que o camponês obtivesse assim a sua reinserção na terra, nas quais a luta constante do camponês em buscar um pedaço de terra para que possa cultivar, usufruir com seu trabalho, um trabalho familiar que não se ligue as imposições do capital. Ainda tendo como entidade que buscava a luta de frente única, encontrava-se o PCB, como partido político que lutava principalmente para que houvesse uma restruturação da sociedade, em que não existisse uma distribuição desigual de terras dentro da sociedade. Ainda podemos verificar a atuação da Igreja Católica em composição da Pastoral da Terra que se criava uma força de luta para que o camponês tivesse, assim, o direito de estar na terra e usufruir de seus benefícios.

Tal concepção nos leva a pensar a respeito de tal processo de articulação que se liga a busca pela terra, a qual torna-se uma dicotomia quando se trata de lutar pela terra e de lutar pela reforma agrária. Assim como evidencia Martins (1988, p.67), ao colocar que o desencontro entre a luta pela terra e a luta pela reforma agrária cruzam o cerne do direito à 
propriedade e passam pelo processo de estruturação de uma corrente em que torna-se uma luta de classes, de pactos políticos e da defesa política da forma de propriedade que temos, tendo assim uma direta mediação por parte do Estado, tendo, desta forma, um sistema continuo de conflitos no campo brasileiro, decorrentes, em sua maioria, das disparidades impostas pela força do capital. A estruturação do campesinato brasileiro mostra os recentes embates decorrentes das contradições presentes no processo de organização do campesinato no território de conquista, outrora subjugado pelo sistema capitalista, em maior parte pelo agronegócio.

A partir dessa visualização de desenvolvimento desiguale de como os modos de produção capitalista atuam na sociedade, observamos que o campo sofre ainda mais com as imposições do capitalismo, tomando assim uma reestruturação das relações não-capitalistas de produção que são desenvolvidas pelo camponês. Dessa maneira, Oliveira (1997) apresenta que:

\begin{abstract}
"Se, de um lado, o capitalismo avançou em termos gerais por todo o território brasileiro, estabelecendo relações de produção especificamente capitalistas, promovendo a expropriação total do trabalhador brasileiro no campo, colocando-o nu, ou seja, desprovido de todos os meios de produção; de outro, as relações de produção não-capitalistas, como o trabalho familiar praticado pelo pequeno lavrador camponês, também avançaram mais". (OLIVEIRA, 1997, p. 11)
\end{abstract}

O que gera uma discussão a respeito de como esse camponês pode ingressar no processo de modificação da realidade de sua permanência na terra, e como suas atividades não capitalista garantem sua proporcionalidade de manutenção e, consequentemente, embate contra a tirania de expropriação por parte dos donos de capital. Tais condições guiadas pelo espírito do capitalismo transformam a sociedade, e assim cria uma forma de resistência em que o trabalho familiar, guiado pelo camponês, condiciona seu crescimento.

\footnotetext{
"Essa contradição tem nos colocado frente a situações em que há a fusão entre a pessoa do proprietário da terra e a do capitalista; e também frente à subordinação da produção camponesa, pelo capital, que sujeita e expropria a renda da terra. E, mais que isso, expropria praticamente todo excedente produzido, reduzindo o rendimento do camponês ao mínimo necessário à sua reprodução física." (OLIVEIRA, 1997, p. 11)
}

O camponês brasileiro subjugado pelas ações do capital tem sua força produtiva reduzida, o que constitui a visualização de que a luta pela terra se torna ainda mais árdua quando se trata de ir contra as grandes transformações impostas pelo crescente avanço dos 
modos capitalistas de produção, e que modifica todos os processos anteriores em que se fazia relação à produção da agricultura. E nestas condições, Oliveira (1997) evidencia que,

"O desenvolvimento das forças produtivas, quer na direção da lógica do capital que produz e reproduz o trabalhador nu, o assalariado, o volante, o "boia-fria", etc., quer na contradição intrínseca dessa lógica produzindo e reproduzindo o camponês, reflete, concretamente, o seu desenvolvimento desigual". (OLIVEIRA, 1997, p.13)

Partimos, então, para entender que o desenvolvimento das forças produtivas, as quais no Brasil cria-se sob uma nova lógica, em que as imposições do capital - no qual o camponês enquanto produtor tem seu mecanismo de produção, sua força de trabalho -, o modo não capitalista de produção, transformado em virtude das ações desse capitalismo estrutural, em que as ações de produção e reprodução estão amplamente condicionas a uma contradição dos mecanismos de produção existente. E, para que entendamos como ocorrem tais contradições, verificamos em Marx (1974), quando ele coloca que,

"Em uma certa etapa de seu desenvolvimento, as forças produtivas materiais da sociedade entram em contradição com as relações de produção existentes, ou o que nada mais é do que sua expressão jurídica, com as relações de propriedade no seio das quais aquela até então se tinha movido. De formas de desenvolvimento das forças produtivas, estas relações se transformam em seus grilhões. Sobrevive então a época de revolução social." (MARX, 1982, p. 2)

E são nestas perspectivas de produção e reprodução que analisamos que o camponês, quando passa a utilizar de suas relações, mediante o uso do trabalho familiar para a produção, possibilita ao grande capitalista, de certa forma, uma redução no custo da mão de obra, mas acarreta também na própria apropriação deste mesmo capitalista latifundiário da utilização de sua produção em excedente.

Dessa maneira, assim, como evidenciado por Oliveira (1997), o processo de compreender como o capital transforma o campo, não em sua maioria, constituirá uma totalidade quando se trata de expandir o trabalho assalariado por toda a extensão do campo, e isso leva então a compreensão que o camponês, mesmo que sofrendo com impactos na sua realidade, não sofrerá uma abrupta exclusão do seu modo de produção familiar. Oliveira (1997) coloca ainda que

“[...] podemos concluir que desse processo de desenvolvimento desigual e contraditório do capitalismo, particularmente no campo, é que estamos diante da sujeição da renda da terra ao capital. O que significa que o capital não expande de forma absoluta o trabalho assalariado, sua relação de 
trabalho típica, por todo canto e lugar, destruindo de forma total e absoluta o trabalho familiar do camponês." (OLIVEIRA, 1997, p. 21)

Esta constituição delimita a estrutura do campesinato, e o faz de refém do processo em que a estruturação do capitalismo cria uma nova condição de desenvolvimento desigual, que mostra como as interposições do capital operam de maneira opressora contra a classe campesina, e contra o campesinato, que é a representado pelo trabalho familiar.

A partir dessas conclusões, observamos que o processo contraditório do desenvolvimento desigual acarreta a transformação do território, assim como é elencado por Oliveira (1997, p.24-25) que coloca que o processo contraditório do desenvolvimento capitalista no campo ocorre primeiramente com a territorialização do capital e, por conseguinte, a revelação de um capital monopolista que tomará para si o território, mesmo que não necessariamente o tome para si, mesmo que tomado pelo capital sem polarização, mas submetido a ele em exploração. Oliveira (1997, p. 25), acrescenta ainda que

\begin{abstract}
"Esse conjunto de contradições que marcam o processo de desenvolvimento capitalista revela, também, que o processo pelo qual o capitalismo se expande no país passa necessariamente pelo domínio do trabalho assalariado nas grandes e médias propriedades e, do predomínio do trabalho familiar, camponês portanto, nas pequenas propriedades ou pequenas unidades de produção." (OLIVEIRA, 1997, 25)
\end{abstract}

Uma relação contraditória, que é um tanto reveladora, é que o aumento do trabalho familiar no campo brasileiro ainda continua mesmo com a ampliação do trabalho assalariado. Observa-se que o primeiro é complementar ao segundo, e isso ocorre devido às contradições do próprio modo capitalista de produção.

\footnotetext{
"Entendemos, portanto, que o desenvolvimento do modo capitalista de produção no campo se dá primeiro e fundamentalmente pela sujeição da renda da terra ao capital, quer pela compra da terra para explorar ou vender, quer pela subordinação à produção do tipo camponês. $\mathrm{O}$ fundamental para $\mathrm{O}$ capital é a sujeição da renda da terra, pois a partir daí, ele tem as condições necessárias para sujeitar também o trabalho que se dá na terra." (OLIVEIRA, 1997, p. 49)
}

No que tange à tais práticas, estas se ligam a concepção de que a sujeição da terra e do trabalho familiar ao capital desvincula-se diretamente do que corresponde ao uso do campo pelo camponês que utiliza da terra para sua manutenção em sociedade. Segundo Oliveira (1997, p. 49), "é preciso entender que a resistência do camponês à expropriação, ao capital, vem de dentro do modo capitalista de produção, e não se expressa num universo particular e isolado". Ocorre, então, uma relação na qual é necessário o entendimento do camponês 
enquanto classe social, não apenas como a força de trabalho, mas um membro da sociedade, que luta para ter seu direito a terra novamente assegurado.

\section{O processo de garimpeirização do posseiro e sua metamorfose em camponês na luta pela terra na Amazônia Oriental}

As estruturas motrizes do processo que gera uma complexidade das relações econômicas, a carência de planejamento estratégico eficaz para a região e os conflitos agrários desembocam na nova realidade que é o garimpo. Vale lembrar que, nessa década, havia focos de garimpagem nos seguintes municípios paraenses: São Félix do Xingu, Altamira, Marabá, Almeirim, Oriximiná, Gurupi, Senador Porfírio, Itupiranga, Jacundá, Porto de Moz e Portel. São os municípios que apresentaram maior concentração de garimpos de ouro, durante o período em que se deu entre 1970 a 1980.

Serra Pelada foi a maior mina de ouro a céu aberto no mundo, localizada no estado do Pará, e durante seu auge foi considerada não apenas o maior garimpo de ouro em toda história da mineração brasileira, mas também o mais violento, pois ali trabalhou mais de 100 mil homens na sua maioria camponeses que deixaram suas famílias assentadas em pequenas parcelas de terras em regime de posses, para aventurar-se em garimpos, em busca de melhoria de vida, sob a perspectiva da febre do ouro no Brasil. Esses garimpos, logo que descobertos, eram controlados pelo governo federal e usados por este como estratégias de desocupação das terras devolutas, até então historicamente ocupadas por posseiros oriundos das migrações nordestinas para a Amazônia Oriental.

Essas terras, sem a presença do chefe de família - metamorfoseado, agora, em garimpeiro -, eram imediatamente destinadas ao processo de privatização, através da ação violenta do GETAT (Grupo Executivo das Terras do Araguaia-Tocantins - GETAT), que fazia uma espécie de "limpeza" da área, expulsando as famílias dos posseiros/garimpeiros que permaneciam nas posses, despejando-as nas periferias de cidades como Marabá, Imperatriz, Parauapebas no Pará e Araguaína e Xambióa no Tocantins. Assim, essas terras eram colocadas, pelo governo federal, inteiramente à disposição do capital estrangeiro. Tais garimpos funcionaram também como áreas de contenção de conflitos engajados na luta pela terra na região, e o ponto máximo desse conflito foi o evento da Guerrilha do Araguaia, nessa mesma região Oriental da Amazônia Legal. Dessa forma entendemos os garimpos da Amazônia como estratégia governamental de "limpeza da área", expulsando os camponeses de suas posses e entregando-as ao capital estrangeiro. Essa estratégia de extrema violência 
culminou com o massacre de posseiros, organizada e/ou apoiada pelo Estado, à medida em que ocorreu o desencanto dos garimpos e da realidade diante da falsa propaganda de enriquecimento fácil. Assim, o posseiro volta pra luta, agora como um camponês sem-terra, organizado em movimentos sociais (como o MST - Movimento Sem Terra) e conscientemente engajado nas lutas de classes em favor de uma reforma agrária mais justa.

Durante o início da década de 1980, dezenas de milhares de posseiros/garimpeiros foram em direção à Serra Pelada, na esperança de ganhar dinheiro com a descoberta do ouro e construir um futuro melhor para si mesmos. No entanto, o que eles encontraram foi um verdadeiro poço sem fundo, de onde muitos nunca voltaram, e tiveram suas famílias expulsas da terra e jogada em bolsões de miséria nas periferias de cidades como Araguaína, Marabá e Altamira.

As transformações sociais, agora condicionadas pelo processo de implementação da busca pelo ouro, cria, então, dificuldades para os posseiros, que devido aos mecanismos de ludibriação pela busca de melhores condições de vida, agora encontram-se metamorfoseados de garimpeiros que se iniciavam no acesso à região dos garimpos. A única maneira de chegar ao local da mina era de avião ou a pé. Além disso, a mina era controlada por terríveis condições e violência, à medida em que as cidades que cresciam ao lado eram notórias em termos de assassinatos e prostituição.

Segundo informações de pesquisa de campo, cada garimpeiro recebia uma área de 2 $\mathrm{m}^{2}$ para escavar, e eles tinham que cavar seus barrancos, enchendo sacos de cerca de 40 quilos com terra e lama. Em seguida, carregavam os sacos pesados até 400 metros de escadas de madeira e cordas (conhecidas por eles como "adeus-mamãe") para o topo da mina, onde o ouro era peneirado. Como eles estavam limitados pelas fronteiras de seus barrancos, a única opção era cavar cada vez mais profundamente. O problema era que, quanto mais profundos fossem seus barrancos, mais perigosos eles se tornavam, pois, as barragens entre os vizinhos ficavam mais frágeis e frequentemente caíam sobre os garimpeiros, enterrando-os junto com o ouro. Os militares brasileiros assumiram as operações para impedir a exploração dos trabalhadores e os conflitos entre garimpeiros e proprietários.

Nesta composição do processo de garimpagem do ouro, encontramos uma figura emblemática, o denominado Coronel Curió, que teve sob o seu controle a administração do garimpo, e comandou o exército na Guerrilha do Araguaia. A partir desse momento, os garimpeiros só poderiam vender o minério extraído para o governo. Ao lado dos barrancos, 
havia um guichê da Caixa Econômica Federal, onde o ouro era pesado e o pagamento feito em dinheiro.

Sobre a constituição desse pagamento, a Caixa decidia os preços e pagava cerca de $60 \%$ a menos que o valor real. O governo militar também passou a proibir mulheres e álcool na mina, fazendo com que a cidade vizinha se tornasse uma cidade de "lojas de prostitutas". Milhares de meninas menores de idade se prostituíram por migalhas de ouro, enquanto cerca de 60 a 80 assassinatos ocorriam nessas cidades todos os meses. A foto a baixo representa os garimpeiros atuando no processo de extração de ouro, no garimpo de Serra Pelada.

Outro garimpo que se configurou como ponto de expulsão camponesa, o Garimpo Castelo do Sonho, comandado por uma figura marcante, no sentido em que a força era o mecanismo principal de subversão do camponês garimpeiro: para as situações em que não se houvesse o controle das terras (controle através de um acordo de venda, haveria resposta violenta, com uso de armas. Essa figura de comando era conhecida como 'Rambo do Pará' ou 'Rambo do Garimpo', um dos maiores detentores das minas de exploração aurífera do Estado do Pará.

A partir daí podemos entender, assim como destaca Brito et al (1997), a respeito dos fatores que contribuíram para a ocorrência do processo de intensificação da exploração de ouro na Amazônia Oriental:

\begin{abstract}
"Entre os fatores que contribuíram para que ocorresse (a valorização do processo de extração mineral) destacamos dois: um aumento significativo de preço do metal, que se registrou em 1971, sendo que esse aumento reflete os sintomas da crise no sistema financeiro internacional e a perda da hegemonia econômica dos Estados Unidos. Soma-se a isto o anúncio pelo Presidente Médici em 1970 de um conjunto de medidas que visavam a transformar a Amazônia em um espaço ("milagroso"), que se encaixaria dentro da perspectiva do milagre econômico, transformando-a em um local de resolver os problemas dos flagelados da seca do nordeste. O Programa de Integração Nacional (PIN) previu a construção de grandes rodovias (Transamazônica, Santarém-Cuiabá) e o Programa de Redistribuição de Terras ficou responsável pelo assentamento dos imigrantes." (Brito et al (1997)
\end{abstract}

Na composição da história do Brasil, o elemento que se destaca no processo de redistribuição de terra foram os garimpos de ouro, principalmente na Região Oriental da Amazônia Legal. Observa-se que diversas vilas foram constituídas em virtude do processo de extração do ouro, de modo que a diversificação econômica foi uma consequência natural de uma sociedade organizada. Nos anos 1970 e 1980, o governo brasileiro adotou a política de colonização da Amazônia, em que se foram criados vários polos de expansão agrícola para 
exploração dos recursos naturais (como é o exemplo do látex, da castanha do Pará, da agropecuária e etc.).

Nesse processo de estruturação para a produção do extrativismo e para a exploração dos recursos naturais pelo latifúndio caiu por terra, a assistência técnica rural associada à pobreza de nutrientes dos solos resultou em dramáticos prejuízos para aqueles que se aventuraram a sair do sul do país. Segundo Veiga(2002, p. 271) observa-se que, quando vários países que quebraram o tratado de Breton-Woods (assinado em 1944, e que fixou o preço do ouro em US\$ 35/onça, sendo 31,1 gramas a onça), o preço do metal experimentou aumento gradual nos anos 70, até atingir o recorde de US\$ 850/onça. Desse modo, essa quebra incentiva a construção de depósitos auríferos que até então não eram considerados econômicos, no sentido de rentabilidade para os grandes mineradores.

Nesse contexto, a garimpagem também tinha conotação positiva de ocupação territorial e era incentivada pelo governo militar como uma forma de estabelecer núcleos de colonização na Amazônia. Desse modo, o garimpeiro posseiro que sai de sua terra, ludibriado pela propaganda divulgada de boca em boca durante a febre do ouro, tiveram as imposições do capital como forte modificador de suas realidades.

\footnotetext{
"Nas décadas de 70 e 80, muitas das áreas descobertas por garimpeiros foram requeridas por empresas de mineração. Muitas delas alegaram depois terem suas concessões invadidas por garimpeiros. Outras, realmente foram vítimas de invasões irresponsáveis. Empresários da mineração passaram a conviver não só com o risco, mas, também, com a insegurança, ao verem seus investimentos sucumbidos e os depósitos minerais dilapidados". (VEIGA, 2002, p. 274)
}

A organização cria uma condição social em que o latifundiário modifica a estrutura de pertencimento, e os garimpeiros, que outrora eram posseiros, sejam retirados para o processo de exploração, tanto no que diz respeito ao extrativismo, quanto no que se diz a respeito da exploração de minério. Desse modo, constitui-se uma nova estrutura que torna vínculo aos donos de capital.

Nos garimpos criaram-se condições para que o garimpeiro, então posseiro, luta por uma melhoria nas condições de vida, ludibriados pela possibilidade de enriquecimento, possam deixar suas esposas com filhos e parta em direção ao garimpo. O latifúndio cria uma nova estrutura de subjugação, na qual a expulsão dos familiares modifica a realidade de tais garimpeiros camponeses da região Amazônica. A atividade garimpeira mostra que as organizações se mantém de forma diferente e cada qual tem uma análise diferente por parte do Estado. (COELHO et ali 2017) apresentam que: 
"O garimpo é considerado ilegal quando é exercido em áreas estritamente proibidas por lei (terras indígenas, áreas de preservação, zonas de fronteira, etc.) ou ainda em áreas nas quais o garimpo tenha sido fechado ou a garimpagem proibida por motivos diversos (riscos ambientais, crimes hediondos, etc.). O Estado sabe da existência ilegal e informal da garimpagem, mas, por razões diversas, não a combate plenamente, nem a regulariza quando possível. Deste modo, não deixa de estabelecer um "quase acordo" com os garimpeiros, com o consentimento das empresas mineradoras. Essas, por sua vez, parecem tolerar os garimpeiros que não ameaçam seus projetos territoriais. Por vezes, inclusive os utilizando como fontes de informação de novas jazidas e como força de trabalho disponível.’(COELHO; WANDERLEY E COSTA, 2017, p. 4)

A nova organização (na qual o Estado busca apenas seu enriquecimento), o latifúndio apresenta uma força em se apropriar da terra. Nestas condições, Coelho; Wanderley e Costa (2017) expressam que as obras de implantação dos garimpos de ouro

“[...] tampouco levaram em consideração índios, posseiros e ribeirinhos que há muito habitavam a região a ser ocupada pelas novas atividades atraídas pelos planos governamentais e pelos projetos encapados pelos agentes capitalistas, nacionais e internacionais. Além dos capitalistas atraídos para a região, garimpeiros, índios, posseiros e ribeirinhos ocuparam, seletivamente, o espaço regional desde a década de 1970 . Na década de 1970, por ocasião da abertura das estradas, vários projetos de colonização foram criados para novos colonos do sul e do nordeste do país. Entretanto, nem todo migrante era contemplado com lotes de terra, o que potencializava luta por terra e a tensão no campo." (COELHO; WANDERLEY E COSTA, 2017, p. 6)

Tais empreendimentos criam uma nova estrutura que modifica as condições materiais e pessoais dos trabalhadores. O garimpeiro, figura que modifica diretamente sua relação de pertencimento, e que busca sua inserção no espaço, transforma sua realidade, a partir das ações do Estado instituídas como chamariz de exploração. O latifundiário, os donos da mineração articulam o capital especulativo de exploração, através da exploração da força de trabalho do garimpeiro.

As condições no processo de exploração do ouro, criado em virtude de uma política estatal voltada para a mineração, adotadas no Brasil, privilegiam os detentores do capital, ou seja, as atividades de mineração industrial e empresarial se dá em detrimento dos garimpeiros descapitalizados que permanecem informais e sem apoio governamental. Seguindo esse raciocínio Coelho; Wanderley e Costa (2017, p. 21) acrescentam que as cooperativas familiares estão envoltas pelos garimpeiros que buscam uma melhoria de vida, e não tem sido fortes o suficiente para remover os problemas sociais/ambientais da garimpagem. 
Estruturasse constituem de ações transformadoras, principalmente no espaço em que estes indivíduos estão inseridos, assim como destacado por Coelho; Wanderley e Costa (2017), para "reduzir as inquietações econômicas dos garimpeiros, que teimam em insistir na possibilidade de um ganho "fácil", que dificilmente se concretiza" (COELHO; WANDERLEY E COSTA, 2017, p. 21), devemos observar que esses garimpeiros-posseiros se perdem dentro do processo de subjugação do capital. Além do mais, as cooperativas funcionam como meio efetivo e simbólico de auxiliar ou assegurar o controle social e territorial sobre os garimpeiros e o recurso mineral, e de fato não se tornam efetivos, pois as imposições do capital falam mais alto que uma organização social.

E quando se trata da organização social que surge perante a iniciativa de construção ferrenha dos garimpos, destaca-se Padre Josimo, figura que, mediante ao processo de expansão do latifúndio, cria uma alternativa para os camponeses que partiram em prol de melhores condições de vida, proporcionando uma nova articulação para aqueles que ficaram na esperança de manutenção de suas terras. Josimo atua como uma figura de resistência, juntamente com as mulheres da região Oriental da Amazônia Legal, em especifico na região do Bico do Papagaio, onde eles criaram uma alternativa para continuar na manutenção de suas posses.

Nascimento, em seu artigo "20 anos com Josimo", retrata como esse homem membro da Igreja Católica cria uma alternativa para escapar dos grilhões da subjugação do capital, e relembra que, durante um longo período, as composições e formações sociais foram de suma importância para a construção da vivência do camponês posseiro. Nascimento coloca que

"Há 20 anos atrás, o Brasil vivia momentos de transformações políticas e econômicas que dinamizavam o cenário das relações políticas. Na região do Bico do Papagaio a situação não se diferenciava. Com o anuncio do fim do regime ditatorial havia uma rearticulação política das oligarquias rurais na chamada Nova República. A luta social se encontrava diante de fortes momentos de tensão e conflito por parte de fazendeiros e trabalhadores rurais que tinham na Igreja, na CPT, nos sindicatos e nos novos movimentos sociais do campo uma esperança em ver realmente a Terra partilhada para todos e todas." (NASCIMENTO, in sitio da CPT 2009)

Tal visão de como as articulações do Estado condiciona uma nova estrutura verifica que a transformação social e material do camponês está ligada diretamente ao subjugo das articulações das oligarquias rurais, e outrora, no período da Guerrilha do Araguaia, pelos latifundiários com o auxílio do Estado. Nessas condições de expropriação e de dominação da população rural, a destituição das posses dos garimpeiros que se aventuraram na busca 
aurífera, pelas mãos de figuras como Cúrio, ou do Rambo do Pará, ou mesmo pelos complexos empresariais da mineração, constituem uma forma de transformação da realidade do camponês. A partir disso, o observamos, como pondera Nascimento, como Josimo foi o agente desse processo:

"Josimo é a testemunha fiel e nos ensina de que vale a pena dar a vida pela
causa do Reino, das comunidades e do povo. Sua morte significou o
compromisso assumido em denunciar as estruturas de morte alimentadas
pelas injustiças políticas de mandos e desmandos de uma oligarquia rural
que ousava (ou ainda ousa) se estabelecer no poder da República. É neste
sentido que Josimo se torna o padre mártir da Pastoral da Terra ao selar com
seu sangue uma opção, um compromisso e um engajamento na defesa dos
oprimidos, em especial, os trabalhadores rurais." (NASCIMENTO, in sitio
da CPT 2009)

As condições da a vida em prol do Reino (de Deus), segundo as crenças de Josimo, davam-se a partir de transformações: só seria possível através da luta, e que se fosse preciso a luta armada seria o caminho para tornar o camponês novamente o verdadeiro dono da terra terra que se encontra sob domínio do latifúndio em companhia do Estado. Do mesmo modo, MARINHO (2018) destaca o processo de atuação do Bispo Dom Pedro Casaldáliga, no Mato Grosso, que condicionou uma luta camponesa em busca de alternativas para o camponês, e que via, assim como Josimo, que os oprimidos devem ter de volta suas terras para produzir e ter o poder sobre a produção, de modo dominar o que de fato era seu até sua tomada pelo capital.

Quando falamos da luta de Josimo e da luta dos camponeses, observamos que a problemática se constitui a partir da década de 1970. O conflito estava instalado, porque em 1970 já se confrontavam dois projetos opostos tendo a terra como base de sua realização. $\mathrm{Na}$ perspectiva do governo militar a modernidade de que a Amazônia era carente não podia realizar-se sem a necessária integração econômica da região nos quadros da economia nacional, de que ela foi suporte, e do capital multinacional.

Pode parecer um despropósito para quem incondicionalmente defende a paz, como era o caso de Josimo, que a luta armada fosse um caminho viável para a realização da Reforma Agrária. Mas certamente sem a institucionalização de que a Comissão Pastoral da Terra foi agente seminal, esse projeto poderia ter sido mais efetivo. Quando se considera o passado imediatamente anterior, as outras experiências de luta pela terra, como foi o caso de Trombas e Formoso (MAIA, 2008) e a experiência das Ligas Camponesas, se percebe que a luta armada parecia ser a tendência natural na Região Araguaia-Tocantins. Frustrada essa 
perspectiva, só restam projeções sobre os caminhos e realidades possíveis se uma revolução camponesa tivesse, de fato, acontecido.

Josimo padeceu de equívoco. Mas o seu trabalho não deixou de ser importante. Devese considerar a cultura de paz tipificada na sua conduta, salvo essa estratégia, a alternativa seria a guerra civil que, muitas vezes, pareceu iminente. De outro lado, a força do seu compromisso expressa no martírio, e a atenção nacional e internacional devotada à região, em função desse gesto extremo, resultou-se de modo proveitoso para os camponeses, porque sensibilizou a opinião pública para a urgência de alguma reforma agrária na região, e, ao mesmo tempo em que provocou uma indisposição social ao grande latifúndio, a medida em que este foi considerado o real assassino do Padre Josimo. A morte de Josimo, portanto, foi a síntese de um processo de desumanização, cujo acontecimento equivale à frustração geral de milhares de homens e mulheres que tinham a Amazônia como sua última esperança a um pedaço de terra para trabalhar.

Fez o mesmo caminho que milhares de outros nordestinos condenados à miséria fizeram na busca da terra da "bandeira verde", aonde se daria a luta com "o cão, o 'capa verde' (MARTINS, 1991, p. 124) mas que, apesar de tudo, parecia, sobretudo depois das campanhas do Estado Militar de "terras sem homens para homens sem-terra" (Id., p. 105; 120) o lugar mais apropriado para a realização dos sonhos. Enquanto síntese de um processo, essa morte, no alvorecer da redemocratização brasileira, foi um grito retumbante de que, para os homens do campo, o Estado Moderno de promoção do bem-estar social não passa de imbróglio.

Essa integração foi uma constante no pensamento político-econômico brasileiro, desde Vargas até o período da Ditadura Militar. A Marcha para o Oeste tinha esse sentido e a construção de Brasília no Planalto Central foi um dos pontos altos dessa estratégia de modernização, para tornar produtiva os espaços amazônicos ocupados por um sertanejo improdutivo. Esse foi o projeto idealizado e empreendido efetivamente por vários governos brasileiros. Oposto a esse projeto, e também em vias de realização, havia o projeto camponês, projeto de fazer a Reforma Agrária e tornar a Amazônia um espaço privilegiado de desenvolvimento da uma estrutura em que possibilitasse a ele, o camponês manter novamente seu processo de produção.

A respeito disso, Ariovaldo Umbelino de Oliveira apresenta sua opinião sobre o que esse projeto representou, projeto que atua como um marco no processo de transformação e consumação dos recursos da Amazônia porque, na verdade, os grandes investidores privilegiados pelo Estado brasileiros representavam os interesses do capital internacional. 
Nesse sentido, é preciso lembrar que havia uma forte penetração da capital internacional na economia brasileira e que, no caso do capital nacional, aquele que tinha maior expressão era exatamente o capital associado ao capital estrangeiro (DREIFUSS, 1981).

Assim, na interpretação de alguns estudiosos do tema, incluindo Martins (1991), Ianni (1979), o projeto capitalista internacionalizou a Amazônia em prejuízo dos interesses nacionais e a maior expressão desse evento foram os próprios projetos oficiais pensados para a região.

\begin{abstract}
"Os grandes projetos lá chegaram. Estão se apropriando de tudo. Explorando tudo. Exportando tudo. A exportação é a palavra mágica que faz mover esse processo de rapina. (...) Esse processo (...) não pode ser contado sem a anuência, decisão e participação dos governos militares do país e seus estrategistas geopolíticos, que são seguramente os maiores responsáveis pela incorporação da Amazônia ao capitalismo mundial de torque monopolista. Seu rastro tem sido o rastro da expropriação". (OLIVEIRA, 1989, p. 15)
\end{abstract}

Esse é o contexto amazônico, e por extensão do Araguaia-Tocantins, no limiar da década de 1970, recorte temporal dessa dissertação. A frustração camponesa ante um governo que havia acenado com um projeto de Reforma Agrária através da proposição do Estatuto da Terra e que, imediatamente, acenava aos capitalistas a possibilidade de usar a mesma região como campo de enriquecimento rápido, não foi suficiente para remover o camponês do seu propósito; ao contrário, os estudos de IANNI (1979) indicam que a promessa de Reforma Agrária foi tomada por autorização implícita para que, nas terras devolutas, se fizesse de fato a realização do projeto camponês, ou seja, a ocupação e trabalho na terra.

\title{
Considerações Finais
}

As condições em que o campesinato se apresenta demonstra como em determinados momentos da era contemporânea, as lutas constantes promovem a organização para guiar a luta de permanência e resistência do campesinato em meio as imposições do capital expropriador. Esse capital, através do latifúndio, monta uma estrutura que leva o camponês a uma constante luta por manutenção em seu território de reprodução, em que ele determina as condições de vivência desse camponês. A partir disso, o desenvolvimento da agricultura camponesa permanece historicamente viva.

Portanto, a agricultura camponesa no Brasil é compreendida não apenas como uma classe social externa ao modo de produção capitalista, mas também, como uma unidade, o 
campesinato, na qual a existência de heterogênea compreenderá as diversidades presentes dentro desta unidade, e a existência de uma reprodução social e cultural desigual pode reproduzir suas peculiaridades e assegurar a manutenção das gerações futuras. Essas gerações devem adequar-se mediante as readaptações, reinvenções ao modo no qual estarão sendo inseridos, mesmo que constantemente direto ou indiretamente explorados e resguardados de suas características fundamentais: o trabalho familiar e a terra.

No objetivo de entender como o campesinato se estrutura como classe social, na Amazônia Oriental a partir da metamorfose do posseiro em garimpeiro e seu retorno a luta pela terra nos seios dos movimentos sociais, observa-se, portanto, uma nova articulação como um novo sujeito engaja-se a em um novo pertencimento de classe social, com uma nova bandeira de luta e uma nova compreensão da sociedade capitalista e suas mazelas históricas, e essa compreensão forja um novo sujeito social na Amazônia Oriental: o camponês metamorfoseado do posseiro, que nesse processo de transformação social adquiriu a consciência de classe.

O camponês é o agente da transformação do território, do espaço de reprodução das práticas cotidianas, o que leva ao camponês uma reprodução do vivenciado, do que ele mantém do passado, e direciona as novas técnicas a partir daquelas carregadas durante gerações. Desse modo, a luta por continuação do modo de vida camponês se manterá viva, e assim ligada diretamente aos movimentos de luta em prol do desenvolvimento do campesinato e de sua reprodução e re-produção por todo território brasileiro.

\section{Referências}

BRITO, Daniel; BRUSEKE, Franz; MATHIS, Armin. Riqueza Volátil: a mineração de ouro na Amazônia. Belém: Cejup, 1997.

CHAYANOV, A. V. Teoria Dos Sistemas Econômicos Não Capitalistas (1924). In:CARVALHO, Horácio M. Chayanov e o campesinato. São Paulo: Expressão Popular, 2014. p. $99-137$

COELHO,Maria Célia;WANDERLEY Luiz Jardim; COSTA Reinaldo. Garimpeiros de Ouro e Cooperativismo no Século XXI. Revista Franco-Brasileirade Geografia, n 33 , ano 2017

COSTA, Delismar Palmeira; MARINHO, Claudiney de Freitas. O Assentamento Mirindiba em Araguaína (TO): um território surgido do conflito. In: Simpósio Internacional de Geografia Agrária, VIII, 2017, Curitiba. Anais... Curitiba, 2017. p. 1-16. 
DREIFUSS, Renê Armand; 1964: a conquista do estado. Petrópolis Vozes, 1981.

FIGUERA, Ricardo Rezende; A Justiça do Lobo: posseiros e padres do Araguaia. SP. Ed. Vozes, 1986

FIORAVANTE, Eduardo. et al. Conceito de Modo de Produção. Tradução e Organização: PhilomenaGebran. Rio de Janeiro: Paz e Terra, 1978. (Coleção Pensamento Crítico, v. 24).

IANNI, Octávio. A luta pela terra: história social da terra e da luta pela terra numa área daAmazônia. Petrópolis: Vozes, 1979.

KAUTSKY, K. A Questão Agrária. Brasília: Linha Gráfica Editora, 1998. (Coleção Pensamento Social-Democrata).

LENIN, V. I. O Desenvolvimento do Capitalismo na Rússia: O processo de formação do Mercado Interno para a Grande Indústria. Tradução e introdução de José Paulo Netto. São Paulo: Abril Cultural, 1982.

MAIA, Cláudio Lopes. The owners of the land: the struggle over the fate of the border The fight for the squatters and Trunks Formoso 1950/1960. 2008. 275 f. Tese (Doutorado em História) - Universidade Federal de Goiás, Goiânia, 2008.

MARX, Karl. O Capital: crítica da economia política: Livro I: o processo de produção do capital. Tradução: Rubens Enderle. São Paulo: Boitempo, 2013.

MARX, Karl. O Capital: crítica da economia política: Livro III: o processo global da produção capitalista. TraduçãoRubens Enderle; edição Friedrich Engels. São Paulo: Boitempo, 2017.

MARINHO, Claudiney de Freitas. Terra de Trabalho e Terra de Negócio no Território da Prelazia de São Félix do Araguaia, Região Nordeste do Estado de Mato Grosso: a atuação religiosa, ideológica, social e política do bispo Pedro Casaldáliga. 2018. 111f. Dissertação (Mestrado em Geografia) - Universidade Federal do Tocantins, Porto Nacional, 2018. , Claudiney de Freitas; LIRA, Elizeu Ribeiro. O Bispo Dom Pedro Casaldáliga ea Opção pelos Pobres da Terra na Região do Araguaia. In: LIRA, Elizeu Ribeiro (org.). Geografia Agrária do Tocantins: campesinato, latifúndio e conflito. Goiânia: Kelps, 2018.

MARTINS, José de Souza. Não Há Terra para Plantar neste Verão: O cerco das terras indígenas e das terras de trabalho no renascimento político do campo. $2^{\mathrm{a}}$ ed. Petrópolis: Vozes, 1988.

Os Camponeses e a Política Pública no Brasil: as lutas sociais no campo e seu lugar no processo político. Petrópolis: Vozes, 1983.

Hucitec, 1991.

Expropriação e Violência: a Questão Política no Campo. São Paulo:

CLAUDEMIRO, Godoy do Nascimento, "20 anos com Josimo", Sitio da CPT, 2009.

doi.org/10.48075/geoq.v13i5.27157 
OLIVEIRA, Ariovaldo Umbelino. Geografia Agrária: Perspectivas no Início do SéculoXXI.In: OLIVEIRA, Ariovaldo Umbelino; MARQUES, Marta Inez Medeiros (org.). O Campo no Século XXI: Território de Vida, de Luta e de Construção da Justiça Social.SãoPaulo: Casa Amarela; Paz e Terra, 2004.

OLIVEIRA, Ariovaldo Umbelino de. Modo de Produção Capitalista e Agricultura. São Paulo: Ática, 1987. (Série Princípios).

.A Geografia Agrária e as Transformações Territoriais Recentes no Campo Brasileiro". In: CARLOS, A. F. A. (Org.).Novos Caminhos da Geografia. São Paulo, Contexto, 1999.

.A agricultura camponesa no Brasil. São Paulo: Contexto, 1997.

.AGeografia das Lutas no Campo. 13 ${ }^{\mathrm{a}}$ ed. São Paulo: Contexto, 2005.

.Amazônia: Monopólio, Expropriação e Conflitos. $2^{\mathrm{a}}$ ed. São Paulo: Papirus, 1989.

.A Longa Marcha do Campesinato Brasileiro:Movimentos Sociais, Conflitose Reforma Agrária. São Paulo: Revista Estudos Avançados, São Paulo, v, 15, p.185-206, 2001.

Ariovaldo Umbelino de. Agricultura Brasileira Transformações Recentes. In: ROSS, Jurandyr (Org.). Geografia do Brasil. São Paulo: Editora da Universidade de São Paulo, 2005.

SHANIN, Teodor. A Definição de Camponês: Conceituações e Desconceituações- o Velho e o Novo em uma Discussão Marxista. Revista Nera, Presidente Prudente, ano 8, n. 7, p. 1-21, julho/dezembro de 2005.

VEIGA, Marcello Mariz da ; SILVA, Alberto Rogério B. ;HINTON, Jennifer J. . O Garimpo de Ouro na Amazônia: aspectos tecnológicos, ambientais e sociais. Ed.Unido/UBC/Cetem, Rio de Janeiro, (p. 268- 295) 2002 